\title{
A Study of Incidence Experience for Taiwan Life Insurance
}

\author{
Ching-Syang Jack Yue ${ }^{\mathrm{a}}$ and Hong-Chih Huang ${ }^{\mathrm{b}}$ \\ ${ }^{a}$ Department of Statistics, National Chengchi University, 64, Section 2, Chi-Nan Road, Taipei, Taiwan \\ 11605 R.O.C. \\ E-mail: csyue@nccu.edu.tw \\ ${ }^{\mathrm{b}}$ Department of Risk Management and Insurance, Research Fellow of Risk and Insurance Research Center, \\ National Chengchi University, Taipei, Taiwan. \\ E-mail: jerry2@nccu.edu.tw
}

Mortality improvement has become a major issue in ratemaking for insurance companies, and ratemaking is especially difficult in Taiwan. There are two reasons for this difficulty: population size and rapid improvement in mortality. Because the history of life insurance in Taiwan is relatively short, all life insurance products are typically offered based on the same experience life table, which is constructed based on the population purchasing all types of life insurance products in Taiwan. In this study, we used experience data from Taiwan life insurance companies to explore whether there are risk factors related to mortality rates. The experience data will also be used to evaluate whether the customers of life insurance companies possess mortality patterns similar to that of the overall population in Taiwan. The Geneva Papers (2011) 36, 718-733. doi:10.1057/gpp.2011.28

Keywords: mortality improvement; experience rate; risk factor; life table; logistic regression

\section{Introduction}

Mortality improvement has been a popular topic in the insurance business, and human life expectancy is likely to increase in the near future. The life expectancy of people in Taiwan has increased significantly since the end of World War II; the change became even more noticeable after the National Health Insurance act was enforced in 1995. For example, the life expectancies of Taiwanese males and females were 72 and 78 years, respectively, in 1998, lower than the respective expectancies of 73 and 79 for U.S. men and women in 1998. According to the Ministry of the Interior of Taiwan, however, the life expectancies in Taiwan have now surpassed those in the U.S. ${ }^{1}$ The life expectancy trends shown in Figure 1 provide a better look at the rapid increase in life expectancy in Taiwan compared to the U.S.

Still, even though on average every person in Taiwan has owned at least two life insurance policies since 2008, approximately $1 / 3$ of the population in Taiwan has never purchased any life insurance product. ${ }^{2}$ It is still unknown whether the population

\footnotetext{
${ }^{1}$ Taiwan data are from www.moi.gov.tw/stat and U.S. data are from the Human Mortality Database.

${ }^{2}$ This is defined as the "Ratio of Insurance Coverage" in the annual report by the Taiwan Insurance Institute. The proportion of people who never purchased life insurance products was 33.44 per cent at the end of 2008 .
} 


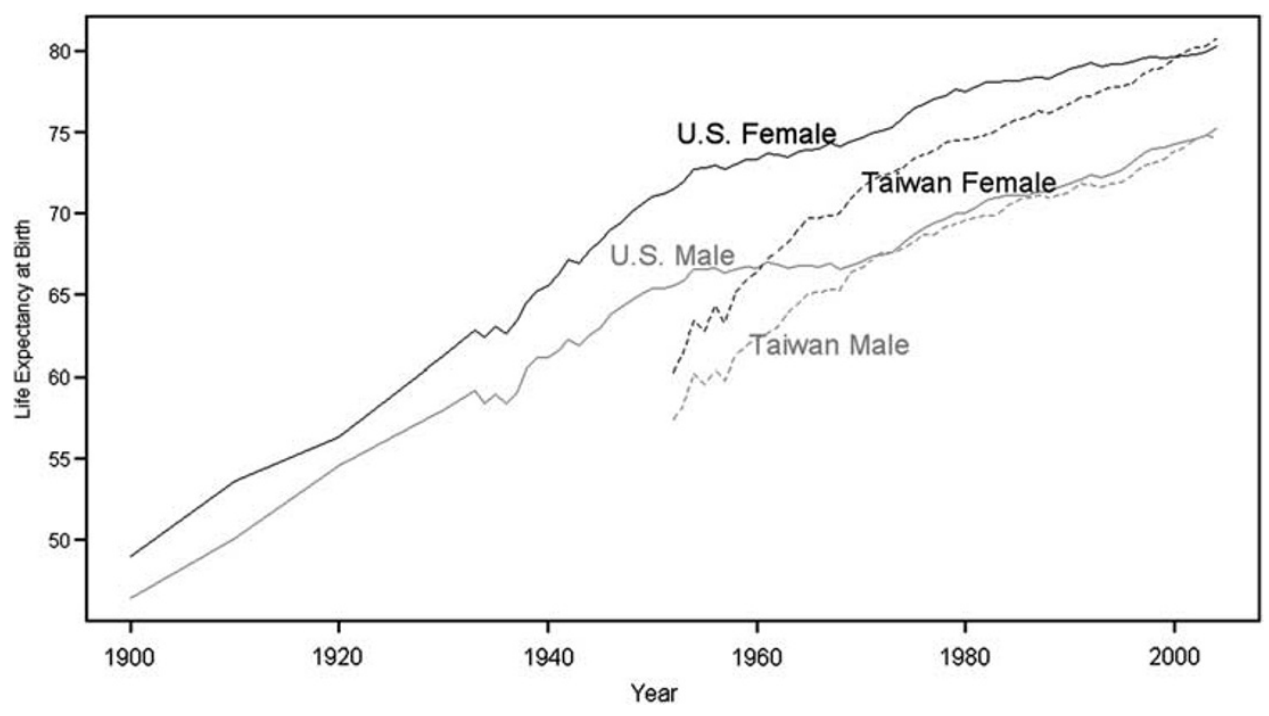

Figure 1. Life expectancies in Taiwan and the U.S.

Table 1 Taiwan insurance policies (1972-2008)

\begin{tabular}{lrr}
\hline Type & No. of policies & Per cent \\
\hline Term life & $4,268,921$ & 8.4 \\
Endowment & $24,132,752$ & 47.3 \\
Whole life & $22,610,097$ & 44.3 \\
\hline
\end{tabular}

purchasing insurance products has a mortality profile similar to that of individuals who do not purchase these products. Because sufficient data on incidence experience is often not available, the pricing of life insurance products is sometimes based on the mortality rates in population life tables. Thus, we sought to explore whether the mortality rates of the population with insurance policies differ significantly from those of the individuals without insurance policies.

Also, the life insurance products in Taiwan can be classified into three groups: term life, endowment and whole life products. Endowment products are the most popular and are probably the most distinct attribute of Taiwan as compared to other countries with regard to life insurance. Table 1 lists the numbers of policies issued between 1972 and 2008. Surprisingly, term life products only account for approximately 8 per cent of policies. The mortality risk levels of individuals with these types of insurance products are likely to be different due to factors such as the coverage term, return on principal and benefit amounts. However, the pricing for these products is based on a single experience life table, ${ }^{3}$ which possibly mixes up groups with different risk levels.

\footnotetext{
${ }^{3}$ The experience life tables used in Taiwan are known as the Taiwan Standard Ordinary Experience Mortality Tables (TSO). The life insurance industry is currently using the $4^{\text {th }}$ TSO or 2002 TSO.
} 
720

In this study, we used the experience data from Taiwan's insurance companies to explore the mortality profiles associated with life insurance. We will introduce the experience data on Taiwan in the next section. The primary objective of this manuscript is to explore whether there are risk factors related to mortality rates other than age, gender and the requirement of a health exam. The secondary objective is to compare the annual mortality improvement levels in the populations with and without life insurance. However, due to a lack of risk factor information, we cannot evaluate the risk factors for the population without life insurance. It is only possible to estimate and compare the annual reduction rates in mortality with respect to age and gender using the Lee-Carter model. These two objectives are covered in the sections "Empirical analysis" and "Mortality improvement". The discussion of this study and related issues is given in the final section.

\section{Data description}

In this study, we analysed the incidence data from life insurance companies in Taiwan for the years 1972-2008 (27 years of data). However, we only used the new policies issued in 1972-2008 because of data availability issues and omitted those policies issued before 1972. The data was collected by the Taiwan Insurance Institute (TII) and cover all life insurance companies in Taiwan. ${ }^{4}$ There are three types of insurance policies included in the study: term life, endowment and whole life.

The experience data includes seven other factors that may be correlated with mortality rates in addition to the policy type: age, gender, health exam, principal repayment, amount of benefits and insurance company size. We will focus on exploring whether mortality rates are correlated with these factors. Age, gender and health exam are three well-known factors that are highly correlated with mortality rates. Generally speaking, the insured who are younger females and have health exams have lower mortality rates. In the following paragraphs, we will address the following factors: principal repayment, benefit amount and insurance company size.

The option of principal repayment is another major attribute of many Taiwan life insurance products. This option makes insurance products similar to investments or savings, which may be why this option is very popular in Taiwan. A term life policy will behave like an endowment policy if the percentage of principal repayment is high. Similarly, a whole life policy will behave like an annuity policy under these circumstances. Heuristically speaking, it is natural to expect that insured individuals who have policies with principal repayment will have lower mortality rates.

Also, the benefit amounts are relatively low compared to the gross national product (GNP) per capita in Taiwan. According to the estimate by the Directorate-General of Budget, Accounting and Statistics (DGBAS), Executive Yuan, the GNP per capita of Taiwan in 2009 was US\$16,997, which is approximately 0.5 million New Taiwan (NT) dollars. The average benefit amount for life insurance products is also approximately

\footnotetext{
4 The experience data was stored by the Insurance Agency Association of the Republic of China (CIAA) before 2007, and TII has been in charge of the data since 2007. TII now maintains all the experience data available from 1972 until the present.
} 
Table 2 Summary of policy numbers derived from Taiwan female insurance data

\begin{tabular}{|c|c|c|c|}
\hline \multirow{2}{*}{ Risk factor } & \multicolumn{3}{|c|}{ Company size } \\
\hline & Small & Middle & Large \\
\hline \multicolumn{4}{|l|}{ Health exam } \\
\hline No & 440,407 & $2,504,019$ & $20,263,883$ \\
\hline Yes & 27,955 & 177,872 & $2,015,745$ \\
\hline \multicolumn{4}{|c|}{ Principal repayment } \\
\hline No & 176,093 & $1,194,873$ & $5,804,234$ \\
\hline Yes & 292,269 & $1,487,018$ & $16,475,394$ \\
\hline \multicolumn{4}{|l|}{ Benefit amount } \\
\hline$<0.5$ million & 192,682 & $1,217,410$ & $13,596,801$ \\
\hline $0.5-1.0$ million & 108,728 & 588,675 & $5,021,068$ \\
\hline$>1.0$ million & 166,952 & 875,806 & $3,661,759$ \\
\hline
\end{tabular}

Note: The benefit amount of 1.0 million is one million New Taiwan Dollars $\approx$ U.S.\$33,000

0.5 million NT dollars, which indicates that under-insurance is an issue in Taiwan. The benefit amounts are separated into three groups by TII: $<0.5$ million, $0.5-1.0$ million and $>1.0$ million. A small proportion of insurance products also require health exams ${ }^{5}$ and are associated with low benefit amounts. Less than 10 per cent of policies include a health exam, and many of them are not mandatory. Because most policies do not require a health exam, it should be interesting to determine whether this phenomenon induces a moral hazard.

The experience data came from 28 insurance companies, which we separated into three groups (small, middle and large) according to the number of policies issued by each company. There were nine companies in the small group, ten in the middle group and nine in the large group to ensure an even distribution. The companies in the small group do not offer more than 100,000 policies, and the companies in the large group do not offer policies of less than 400,000 . The total number of policies in the small, middle and large company groups is 485,$105 ; 1,936,050$ and $24,555,354$, respectively. Because the proportion of individuals in the small company group is less than 2 per cent, we will focus on comparing the mid-sized and large companies. Because the large companies have a larger capacity (or tolerance) and more marketing choices, the mortality rates of customers at the large companies are likely to be higher.

Tables 2 and 3 provide the summary statistics for the experience data according to company size. It seems that companies of different sizes have their own marketing strategies. For example, small companies have fewer policies with small benefit amounts, whereas large companies have fewer policies with principal repayment. Overall, most policies have very low benefits, and most policies do not require health exams. Interestingly, more than 70 per cent of policies include principal repayment. If

\footnotetext{
${ }^{5}$ The health exam usually covers general items, including height, weight, blood pressure and pulse. If the benefit amount is high, sometimes blood test and urine test are required.
} 
Table 3 Summary of policy numbers derived from Taiwan male insurance data

\begin{tabular}{|c|c|c|c|}
\hline \multirow[t]{2}{*}{ Risk factor } & \multicolumn{3}{|c|}{ Company size } \\
\hline & Small & Middle & Large \\
\hline \multicolumn{4}{|l|}{ Health exam } \\
\hline No & 443,312 & $2,415,117$ & $20,312,461$ \\
\hline Yes & 26,578 & 200,704 & $2,184,334$ \\
\hline \multicolumn{4}{|c|}{ Principal repayment } \\
\hline No & 182,588 & $1,173,166$ & $6,153,976$ \\
\hline Yes & 287,302 & $1,442,655$ & $16,342,819$ \\
\hline \multicolumn{4}{|l|}{ Benefit amount } \\
\hline$<0.5$ million & 178,209 & $1,117,410$ & $12,844,392$ \\
\hline $0.5-1.0$ million & 114,953 & 585,970 & $5,421,639$ \\
\hline$>1.0$ million & 176,728 & 912,441 & $4,230,764$ \\
\hline
\end{tabular}

Note: The benefit amount of 1.0 million is one million New Taiwan Dollars $\approx$ U.S. $\$ 33,000$.

we exclude the endowment products (47.3 per cent in Table 1), we can analyse the term life and whole life products exclusively. The finding that emerges is that approximately half of the term life and whole life products include principal repayment, which is a very high percentage.

We shall continue exploring the experience data in the next two sections. We first determine whether there are mortality-related factors in the next section and then compare the mortality rates in the population table to those in the experience table.

\section{Empirical analysis}

Because the population of Taiwan is not large (approximately 23 million), the observed mortality rates for each age group will fluctuate significantly between two consecutive years. To reduce variations, the experience data was partitioned into five age groups for each year. Also, the youngest age group is $0-14$ (ages 0 to 14 years), and the highest age group is $80+$ (ages 80 years and over). This makes it possible to accumulate sufficient claim data. We found that there are four factors related to mortality rates: principal repayment, company size, health exam and benefit amount. We shall summarise the major findings in this order.

The mortality rates for term life, endowment and whole life policies are very similar, but there are obvious differences if these policies are separated, based on whether they include principal repayment. We only used the data on term life and whole life policies in analysing the effect of principal repayment because, by definition, an endowment policy must include principal repayment. Because the nature of principal repayment is similar to that of an annuity and/or endowment, that is, it offers payment upon survival, it is not a surprise that mortality rates are smaller for policies with principal repayment. We shall demonstrate the case of male mortality rates as shown in Figure 2. The male mortality rates associated with the term life policies with principal 


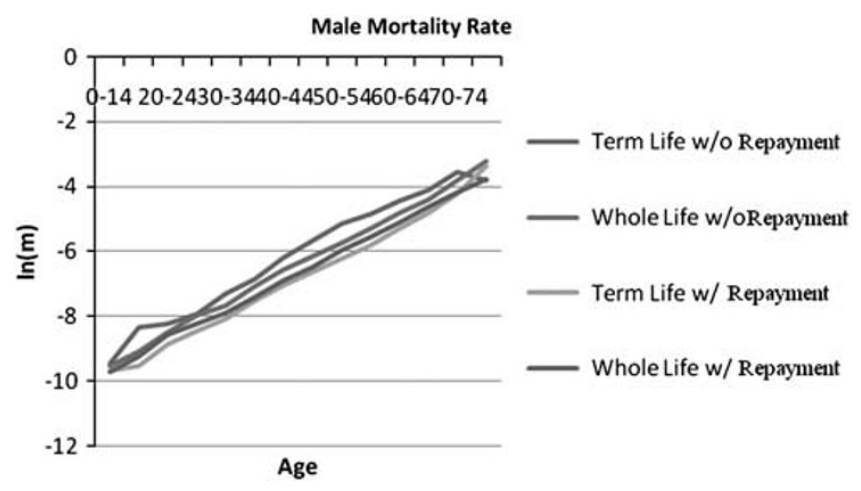

Figure 2. Mortality comparison for principal repayment (Taiwan Male).

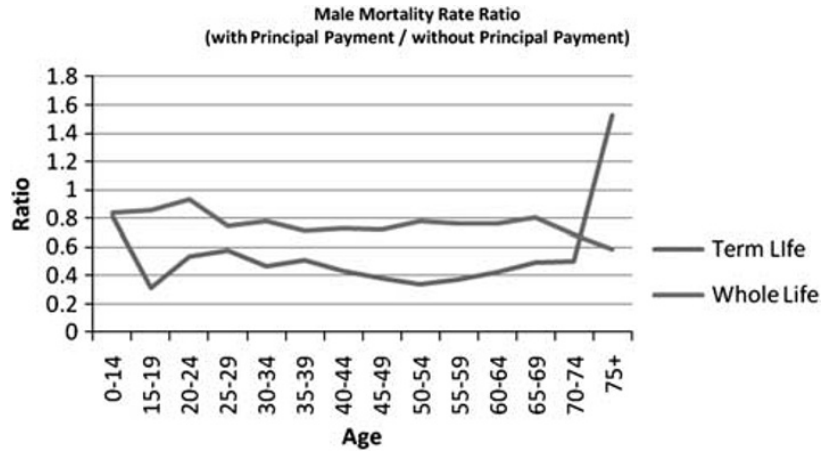

Figure 3. The mortality ratio for principal repayment (Taiwan Male).

repayment are the lowest in all groups, and those associated with the term life policies without principal repayment are the highest. The differences are less obvious for the whole life policies, and the mortality rates under the condition of principal repayment are still lower.

An additional comparison can be made using mortality ratios (Figure 3). On average, the difference between the male mortality levels based on whether principal repayment is included is approximately 50 per cent for the term life and 20 per cent for the whole life policies. This is a very significant difference in the pure premiums of these policies, especially for the term life policies, even after considering the interest rate. The difference between the pure premiums for the term life policies when principal repayment is included vs. when it is not is approximately 50 per cent. The pure premium difference for the whole life policies is sensitive to the interest rate, of which it is a decreasing function.

In analysing company size, we first looked at the summary statistics (Table 4). Because the small company group provides less than 2 per cent of the policies, we focused on comparing the mid- and large-sized companies. For both males and females, the mid-sized companies target on the whole life policies (about 65.6 per cent), 
Table 4 Summary of policy numbers with reference to company size

\begin{tabular}{llrrr}
\hline Gender & Company size & Term life & Endowment & Whole life \\
\hline Male & Large-sized company & $1,584,231$ & $11,352,337$ & $9,560,227$ \\
& Mid-sized company & 239,357 & 654,538 & $1,721,926$ \\
& & & & \\
Female & Large-sized company & $2,165,901$ & $10,952,936$ & $9,160,791$ \\
& Mid-sized company & 223,935 & 712,346 & $1,745,610$ \\
\hline
\end{tabular}
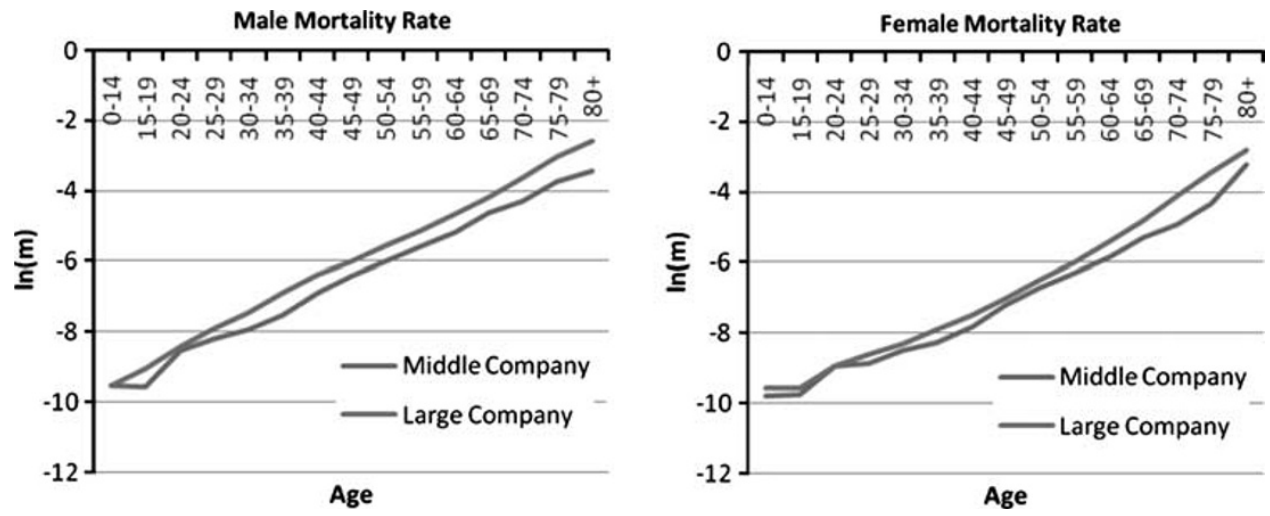

Figure 4. Mortality comparison based on company size (Taiwan Male).

whereas approximately 50 per cent of the policies offered by the large companies are endowment policies. On the other hand, in mid-sized companies, fewer than 1 per cent of the policies are term life policies, and the corresponding figure for large companies is approximately 9 per cent.

The overall mortality comparisons based on company size are presented in Figure 4. The mortality rates presented for mid-sized companies are generally lower in all age groups, and the difference is more obvious for males. One possible interpretation is that mid-sized companies are less tolerant of losses and thus are more risk-sensitive. In addition, the average cost of issuing a new policy is likely to be higher for mid-sized companies. The lower mortality rates would provide a better survival opportunity for mid-sized companies.

As expected, the mortality rates associated with plans that include health exams are lower (details of these findings will not be presented). The benefit amounts were divided into three categories: less than $\$ 0.5$ million NT dollars, $\$ 0.5-1.0$ million NT dollars and more than $\$ 1$ million NT dollars. For term life insurance, the policies with benefit amounts of less than 0.5 million NT dollars have the lowest mortality rates, whereas those with benefit amounts of more than 1.0 millions NT dollars have the highest mortality rates (Figure 5). The patterns reverse for endowment insurance, namely the mortality rates are the lowest for benefit amounts greater than 1.0 million NT dollars. This important finding implies that insurance companies should use 

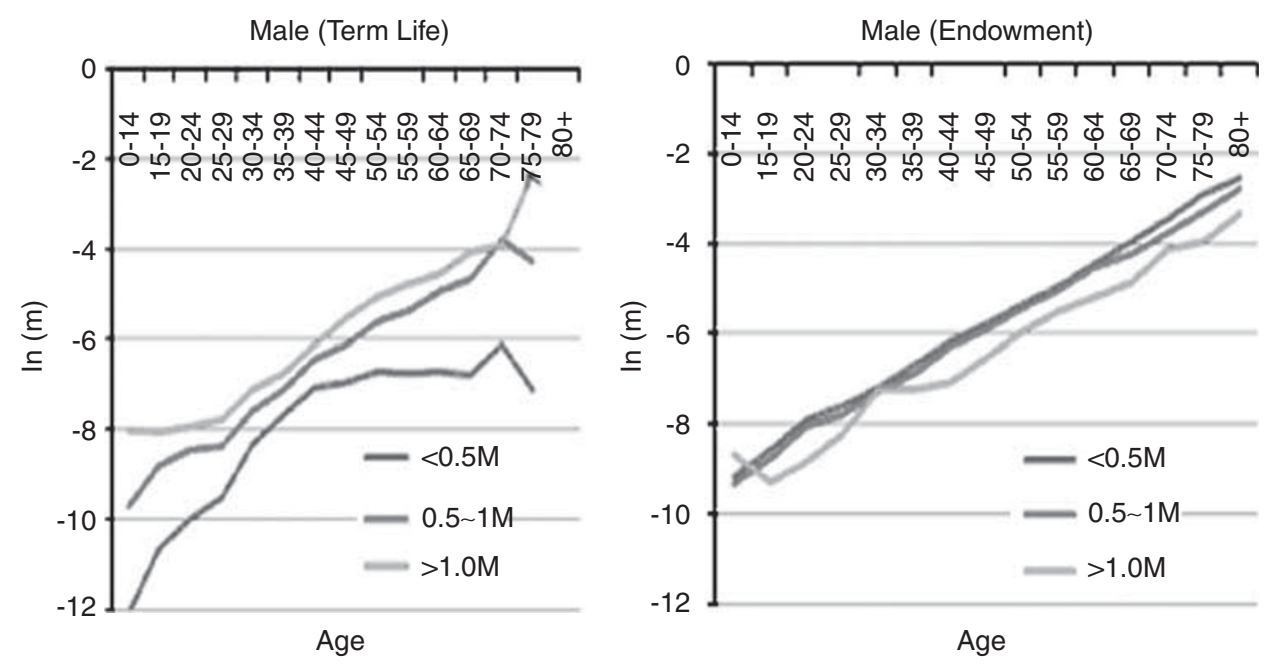

Figure 5. Mortality comparison of benefit amounts (Taiwan Male).

Table 5 Summary of logistic regression for mortality rates

\begin{tabular}{lccccccc}
\hline Predictor & Coef & $S E$ & $Z$ & P-value & Odds ratio & 95\% C.I. \\
\cline { 3 - 7 } & & & & & & Lower & Upper \\
\hline Constant & -9.0498 & 0.0166 & -545.11 & $<0.0001$ & & & \\
Gender & -0.8149 & 0.0028 & -286.56 & $<0.0001$ & 0.44 & 0.44 & 0.45 \\
Age & 0.0726 & 0.0004 & 191.45 & $<0.0001$ & 1.08 & 1.07 & 1.08 \\
Age`2 & 0.000042 & 0.0000036 & 11.55 & $<0.0001$ & 1.00 & 1.00 & 1.00 \\
Health exam & -0.0594 & 0.0034 & -17.66 & $<0.0001$ & 0.94 & 0.94 & 0.95 \\
Principal repayment & -0.1653 & 0.0030 & -54.46 & $<0.0001$ & 0.85 & 0.84 & 0.85 \\
Benefit amount & -0.2357 & 0.0073 & -32.30 & $<0.0001$ & 0.79 & 0.78 & 0.80 \\
Company size & 0.2879 & 0.0057 & 50.57 & $<0.0001$ & 1.33 & 1.32 & 1.35 \\
\hline
\end{tabular}

different mortality rates for pricing according to their benefit amounts to avoid biased selection. We can use this information to further differentiate mortality risk (for term life policies) and seek a better way to address longevity risk (endowment).

In addition to using graphs to show the different mortality rates with respect to the risk factors analysed, we also conducted logistic regression to demonstrate the differences. Table 5 shows the regression results. As expected, all the coefficients of the risk factors are significant. It should be noted that except for the continuous variable "age", all variables (including the dependent variable, $0 / 1$ indicating survival/death) are indicator variables, with $0 / 1$ indicating No/Yes. The variable "benefit amount" is defined as 1 if it is larger than 1 million, and the variable "company size" is 1 for large companies. Comparing the effect of the risk factors principal repayment, company size and benefit amount, we found that the effect of company size is the largest and that the 
effect of principal repayment is the smallest. Still, all three factors have a smaller impact on mortality risk than the factor gender. However, their effects are greater than the influence of the health exam factor, which suggests that including these risk factors may help to reduce the possibility of moral hazard or biased selection.

In this section, we found that four factors (principal repayment, company size, health exam and benefit amount) are highly correlated with mortality risk. Some of the results are quite unique, and further study should be undertaken to determine what causes differences in mortality risk. Also, the level of mortality risk is very significant, which suggests that insurance companies in Taiwan should pay more attention to pricing life insurance products. Using a single experience life table (TSO) is not appropriate for calculating pure premiums, and insurance companies need to take into account the appropriate risks to avoid risk aversion.

\section{Mortality improvement}

In this section, we will continue our empirical analysis by comparing the mortality rates based on population data to those based on experience data using the Lee-Carter model, which was proposed by Lee and Carter. ${ }^{6}$ According to this model, the central mortality rate $m_{x, t}$ should be consistent with the following equation

$$
\ln \left(m_{x, t}\right)=\alpha_{x}+\beta_{x} \kappa_{t}+\varepsilon_{x, t}
$$

where parameter $\alpha_{x}$ describes the average age-specific mortality, $\kappa_{t}$ represents the improvement in the general mortality level over time, and the decline in mortality at age $x$ is captured by $\beta_{x}$. As in the previous section, the data is presented in five year groups, but we aggregated three years of data when using the Lee-Carter model to acquire more observations.

The coefficients $\alpha_{x}$ and $\beta_{x}$ have similar values for the entire population of Taiwan and for the people purchasing insurance products. However, the mortality improvement over time, which can be expressed in terms of $\kappa_{t}$, behaves quite differently in these two groups. As shown in Figure 6, the slope of $\kappa_{t}$ is steeper for the people purchasing insurance products, which indicates obvious mortality improvement. Because the life insurance industry is less than 40 years old in Taiwan (it was started in the 1970s), relying on population data to develop experience rates is sometimes unavoidable. However, based on our findings, it seems that this procedure must be handled with care because the level of mortality improvement is likely to be different. If the annuity table is constructed using the population data, the premiums will be underestimated.

In addition to obtaining the annual improvement rate, we also determined the improvement rate of each age group. Figure 7 compares the annual improvement rates of the 5 age groups (or $\beta_{x} \kappa_{t}$ in Eq. (1)). For both males and females, the differences between the improvement rates based on the population and experience data are larger for the younger age groups. The gaps decrease as age increases, and there is no

\footnotetext{
${ }^{6}$ Lee and Carter (1992).
} 


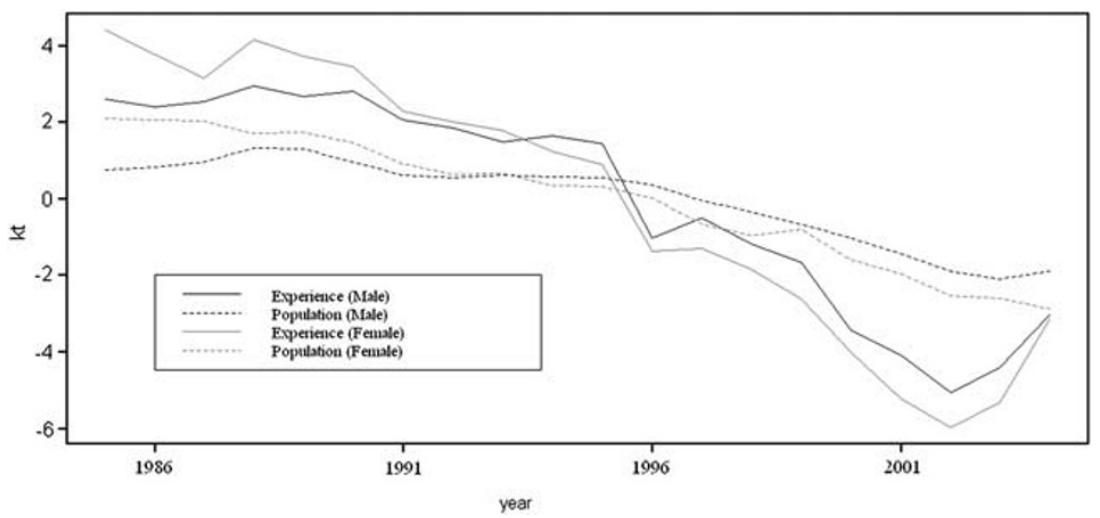

Figure 6. Mortality improvement of the population vs. experience data in Taiwan.

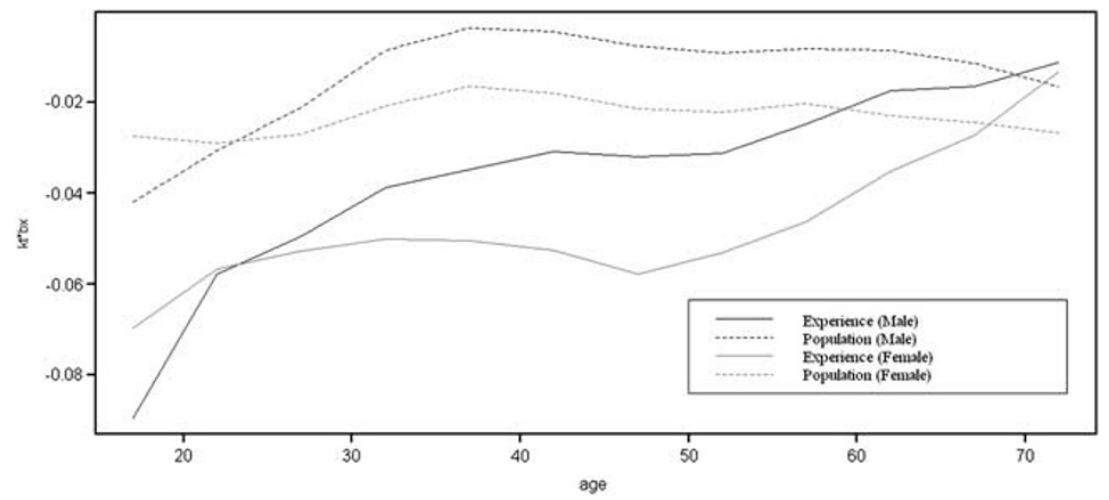

Figure 7. Mortality improvement of the population vs. experience data (by age group).

difference among people aged 70 years and above, in which the annual improvement is about 2 per cent (or in which there is a 2 per cent mortality reduction rate). The females show a greater mortality improvement than the males, and the rates are higher for the younger groups. To use the Lee-Carter model in Figures 6 and 7, we required complete data for all age groups. However, because there was not enough data for the 20s and 70s age groups from the 1970s and early 1980s, we used the data after 1984 with the Lee-Carter model.

In the rest of this section, we will evaluate the pricing of insurance products using the experience data based on the results obtained from the Lee-Carter model. More specifically, we will calculate the pure premiums paid for whole life, annuity and endowment products and will determine the difference between the figures obtained using the regular period life tables (without considering mortality improvement) and the cohort life table (considering mortality improvement). The period life tables considered are the 2002 TSO (also known as the $4^{\text {th }}$ Taiwan Standard Ordinary Experience Mortality Table), the 2002 Annuity Table and the 1999-2001 Taiwan Complete Life Table (or $9^{\text {th }}$ Taiwan Period Life Table; $9^{\text {th }}$ TPL). 


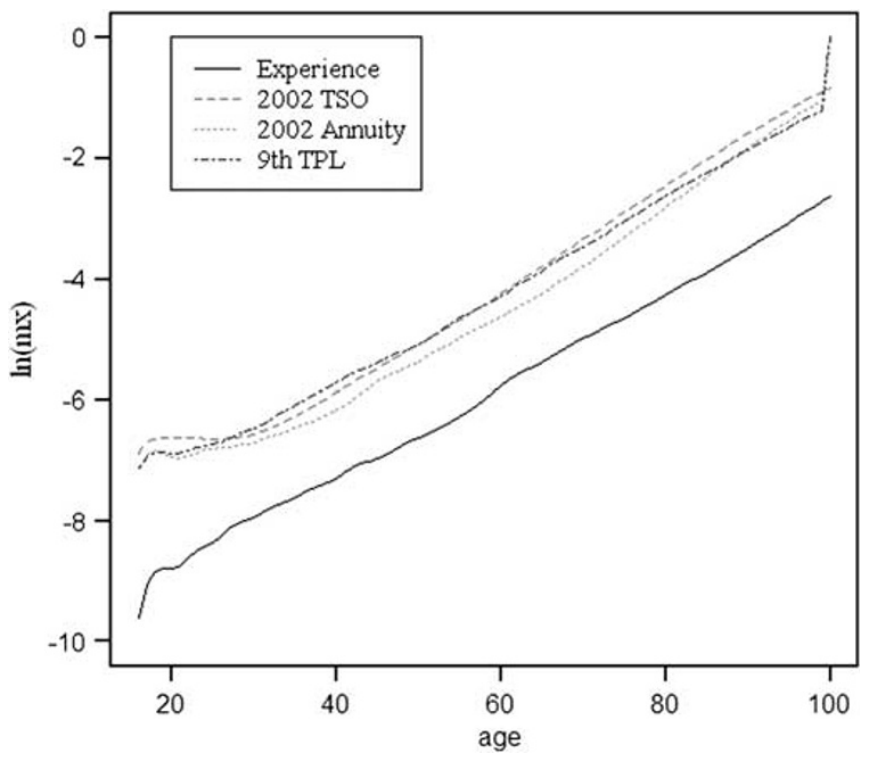

Figure 8. Male mortality rates of various life tables.

Currently, the 2002 TSO is still used to calculate the premium and reserves for life insurance products in Taiwan even though the mortality rates are already out-of-date. Other countries in Asia, such as Japan and South Korea, also face a similar situation. Next, to determine the amount of mispricing (over-estimation) that occurs in practice, we compare the premiums calculated using the official life table (2002 TSO) and those calculated using cohort mortality (Lee-Carter model). The male mortality rates (as presented in Figure 8) are used to demonstrate the differences between the results obtained using these life tables. The experience data (data period: 2004-2008) apparently yields the smallest mortality rates, and other life tables yield similar results. Note that the 2002 annuity table was used to price the annuity products in Taiwan.

Because neither the 2002 TSO nor the $9^{\text {th }}$ TPL includes mortality improvement, the pure premiums of life insurance products will be overestimated. To account for the over-estimation insurance companies in Taiwan usually adapt with lower mortality rates. However, since between 80 and 90 per cent of the 2002 TSO mortality rates are used for the premium calculation, the over-estimation cannot be entirely resolved. Table 6 lists the overestimation percentages for the whole life policies at different issue ages when these period tables are compared to the cohort life table based on the experience data. The interest rate is assumed to be 3 per cent, and it is assumed that no individuals will survive beyond the age of 100 .

The overestimates are more obvious for females as in Figure 7 and are larger for younger age groups (up to 90 per cent). Even when a policy is issued for a 40-year-old man, the overestimate is at least 30 per cent. (The differences will be even larger for the term life policies according to our calculations.) Because the overestimate of the pure premium is non-negligible, many life insurance companies return the overpaid 
Table 6 Percentages of premium overestimations in whole life policies

\begin{tabular}{lcccc}
\hline Issue age & 20 & 30 & 40 & 50 \\
\hline 2002 TSO & & & & \\
Male & 54.6 & 47.0 & 39.4 & 31.7 \\
$100 \%$ & 49.1 & 42.1 & 35.0 & 27.9 \\
$90 \%$ & 43.2 & 36.7 & 30.2 & 23.7 \\
$80 \%$ & & & & 75.1 \\
Female & 90.6 & 86.7 & 75.6 & 69.6 \\
$100 \%$ & 83.8 & 80.3 & 68.6 & 63.2 \\
$90 \%$ & 76.1 & 72.9 & & 30.1 \\
$80 \%$ & & & 38.5 & 75.2 \\
$9^{\text {th }}$ TPL & & & 81.7 & \\
Male & 54.1 & 46.6 & \\
Female & 90.6 & 86.8 & & \\
\hline
\end{tabular}

Table 7 Premium underestimation percentages for annuity policies (males)

\begin{tabular}{|c|c|c|c|c|}
\hline Deferred period/age & 20 & 30 & 40 & 50 \\
\hline \multicolumn{5}{|l|}{2002 annuity } \\
\hline 0 & 8.2 & 9.5 & 10.9 & 12.0 \\
\hline 10 & 26.7 & 27.9 & 29.3 & 30.6 \\
\hline 20 & 33.3 & 36.6 & 41.6 & 49.8 \\
\hline \multicolumn{5}{|l|}{$9^{\text {th }} T P L$} \\
\hline 0 & 10.9 & 13.4 & 16.1 & 18.8 \\
\hline 10 & 35.1 & 38.4 & 42.1 & 46.9 \\
\hline 20 & 44.4 & 51.2 & 61.3 & 77.9 \\
\hline
\end{tabular}

premium if the observed mortality rates are lower than a pre-defined value (i.e., in participating policies or profit policies).

We calculated the pure premiums for annuity products as well, considering immediate and deferred annuity. Again, the interest rate is 3 per cent, and the ultimate age is 100. As shown in Tables 7 and 8, the underestimates are significant (more so for females). For example, Table 8 shows that the underestimate by insurance companies in Taiwan is currently 63.2 per cent for a 20 -year-deferred whole life annuity policy issued to a female of age 40 .

Table 6 indicates that insurance companies will profit from issuing a life insurance policy because they will overestimate the premium. However, an endowment policy is a combination of the pure life and pure endowment policies. Insurance companies overestimate the premiums for the pure life portion of the coverage and underestimate the pure endowment portion. Figure 9 shows the pricing differences between endowment policies with 10 per cent annual principal repayment calculated using the 2002 TSO mortality rates and the experience rates with mortality improvement. 
Table 8 Premium underestimation percentages for annuity policies (females)

\begin{tabular}{lrrrr}
\hline Deferred period/age & 20 & 30 & 40 & 50 \\
\hline 2002 annuity & & & & \\
0 & 8.8 & 11.7 & 15.7 & 21.3 \\
10 & 32.4 & 37.7 & 45.2 & 56.6 \\
20 & 39.8 & 48.7 & 63.2 & \\
$9^{\text {th }} T P L$ & & & & 24.5 \\
0 & & & 18.0 & 65.3 \\
10 & 9.9 & 13.3 & 51.5 & 106.1 \\
20 & 36.2 & 42.5 & 72.9 & \\
\hline
\end{tabular}
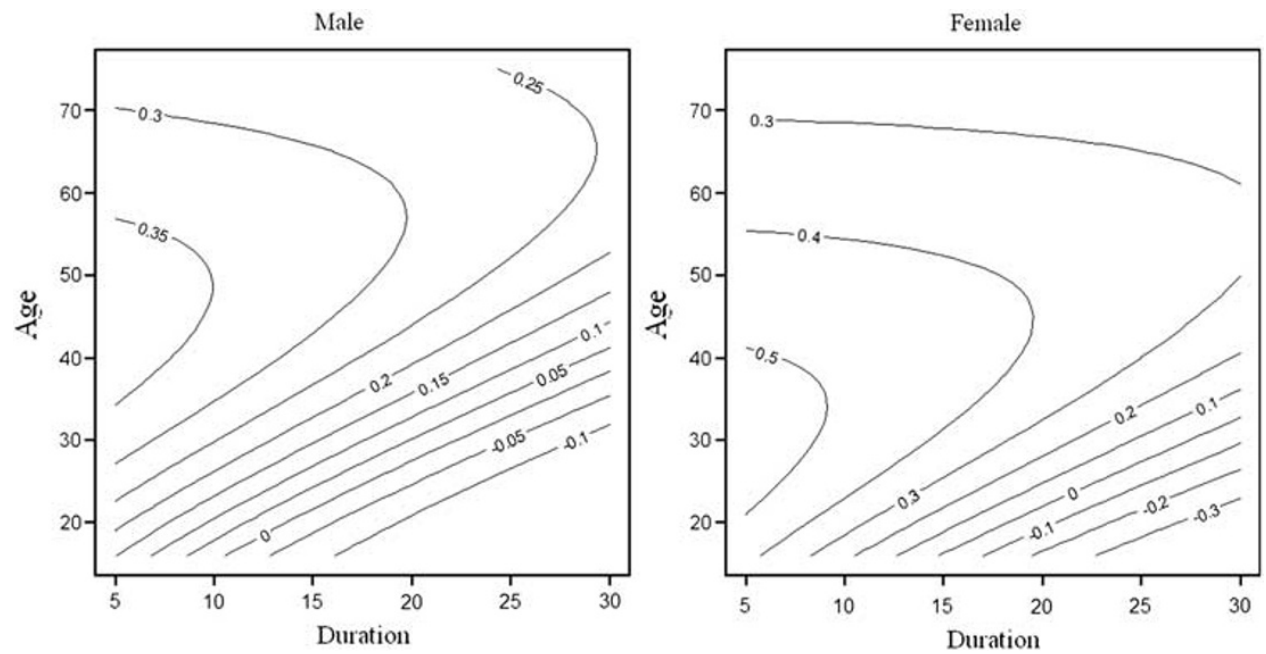

Figure 9. Pricing differences for endowment policies (with 10 per cent annual principal repayment) (2002 TSO vs. experience).

In Figures 9 and 10, the $X$-axis (duration) is the policy period, the $Y$-axis is the issuing age of the insured person and the contour values are the under-/overestimates of the pure premiums. Positive/negative values indicate that the insurance companies over-/ underestimate pure premiums. For example, Taiwan's insurance companies can overestimate more than 30 per cent of the pure premium for a ten-year endowment policy issued to a female of age 20 and underestimate more than 30 per cent of the pure premium for a 30-year endowment policy issued to a female of age 20 .

Because the endowment policy is categorised as a life insurance policy, insurance companies may think that they will always make a profit from life insurance policies due to mortality improvement. On the contrary, however, insurance companies may also experience a deficit of more than 30 per cent if they issue endowment policies. This is an important finding, especially for Taiwan, because 

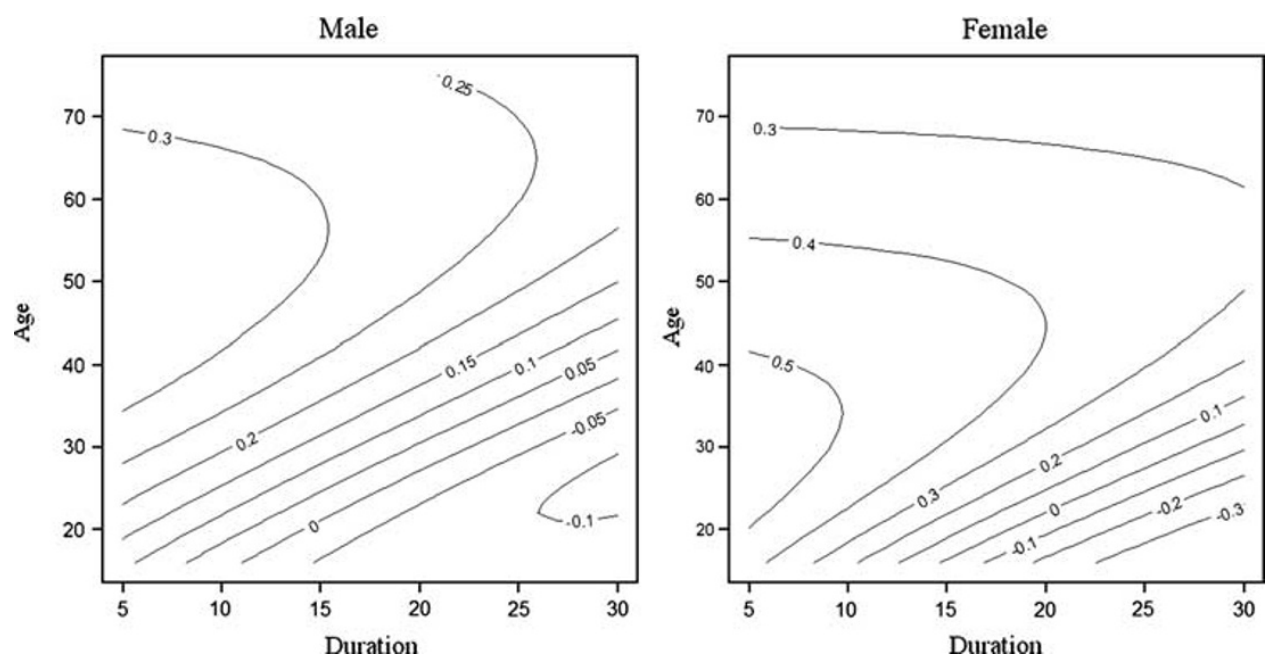

Figure 10. Pricing differences for endowment policies (with 10 per cent annual principal repayment) ( $9^{\text {th }}$ TPL vs. experience).

endowment policies are very popular in Taiwan's insurance market. The results are similar if the premiums are calculated based on the $9^{\text {th }}$ TPL and Taiwan experience rates (Figure 10).

\section{Discussion}

Continuing mortality improvements and, therefore, increasing life expectancy are evident in many countries, and many believe that life expectancy will continue to increase. This increase has changed our living arrangements, especially after retirement, and pension products are becoming more popular. However, because mortality rates are likely to decline continuously in the future, annuity pricing is very difficult. This finding is especially true of countries without sufficient historical data. In this study, we used the experience data from Taiwan insurance companies to explore the mortality profiles of experience rates and to investigate potential problems.

The primary objective of this study was to identify mortality risk-related factors and to include these factors in the premium calculation process to avoid moral hazard and biased selection. Our findings indicate that in addition to age, gender and health exam, there are three new mortality risk factors: principal repayment, benefit amount and insurance company size. However, contrary to our expectations, the mortality rates associated with the three types of life insurance policies (term life, endowment and whole life) do not differ significantly. Instead, the new risk factors are more correlated with mortality rates than with policy type.

Principal repayment probably plays a rather unique role in Taiwan. Policies that include this option seem to be associated with lower mortality rates. Also, mid-sized 
Table 9 Premium ratio of experience/population mortality improvement (whole life)

\begin{tabular}{lcccc}
\hline \multicolumn{4}{c}{ Experience premium/Population premium } \\
\hline Issue age & 20 & 30 & 40 & 50 \\
Male & $82.8 \%$ & $83.3 \%$ & $85.6 \%$ & $88.6 \%$ \\
Female & $71.4 \%$ & $69.4 \%$ & $67.9 \%$ & $66.9 \%$ \\
\hline
\end{tabular}

companies report lower mortality rates than do large companies. Policies that include health exams and larger benefit amounts are also associated with lower mortality rates. These results suggest that consumer behaviour in Taiwan might be different from other countries (e.g., term life policies are not popular in Taiwan). Insurance companies should use two different pricing bases for mortality rates to avoid moral hazard and to protect policyholder rights. The risk factors are not likely to be the same in different countries, and we suggest a full exploration of the experience data from every country.

The secondary objective of this study was to compare the current mortality rates and mortality improvement obtained using the experience data and the whole population data in Taiwan. The current experience mortality rates are much lower and also exhibit larger mortality improvement. The differences in improvement are especially significant for the female groups and the younger age groups, whereas they are not as obvious for the older age groups. We use the premium of whole life policy as a demonstration. The mortality improvements of the experience data are significantly different from those of the population data (Table 9). Because the degree of mortality improvement is very significant in Taiwan, use of the traditional period life table to calculate pure premiums for insurance policies is no longer advisable. Decreasing mortality rates may cause either overestimated or underestimated pure premium calculations.

For example, Figure 9 shows that Taiwan's insurance companies can either overestimate or underestimate pure premiums by more than 30 per cent for endowment policies (with 10 per cent annual principal repayment) issued to females of age 20 depending on the duration of the policy. This is an important finding. Endowment policies are also very sensitive to mortality changes. These results differ from previous studies and suggest that the mortality improvement may lead to undercharging in premium calculations not only for annuity products, but also for life insurance products. Both the governments and life insurance companies must work harder to address longevity risk and the decreasing mortality rates.

In addition to these findings, we also identified other serious problems in Taiwan's life insurance industry. The history of life insurance in Taiwan is not long, and the experience data has not been fully explored. Very few insurance companies have their own experience tables, and everyone relies on the same experience tables (2002 TSO and 2002 Annuity Table) except for the largest companies. Therefore, it is difficult for small- and mid-sized companies to compete with large companies based on the same mortality rates. As shown in Figure 4, the mid-sized companies have lower mortality rates, which allow them to compete with the large companies. 


\section{References}

Human Mortality Database, www.mortality.org.

Lee, R.D. and Carter, L.R. (1992) 'Modeling and forecasting U.S. mortality', Journal of the American Statistical Association 87: 659-671.

\section{About the Authors}

Ching-Syang Jack Yue is a Consultant and Actuary, as well as a Professor at the Statistics Department, National Chengchi University in Taiwan. He served as the Chair of the Statistics Department in 2003-2005 and currently is the Chair of the Taiwan Population Association. He focuses his research on the longevity study, and is a leader of the longevity research group at College of Commerce, National Chengchi University.

Hong-Chih Huang is the Professor and Head of Department of Risk Management and Insurance at the National Chengchi University in Taiwan. He received his PhD at the Department of Actuarial Mathematics and Statistics at Heriot-Watt University in the U.K. His research interests cover asset liability management, asset allocation, longevity risk and pensions. 